\title{
Cylinder Axis Agreement: Unexpected Scenarios
}

\author{
Karim Mahmoud Nabil if \\ Department of Ophthalmology, Faculty of \\ Medicine, University of Alexandria, \\ Alexandria, Egypt
}

This article was published in the following Dove Press journal: Clinical Ophthalmology

Background: The purpose of this retrospective study was to evaluate cylinder axis agreement between manifest refraction (MR), cycloplegic refraction (CR), Allegro Oculyzer II and Allegro Topolyzer-Vario.

Methods: We included 82 patients (32 males and 50 females, $28.1 \pm 8.7$ years old), with 156 eyes scheduled for wavefront optimized laser refractive surgery, photorefractive keratectomy (PRK) in 50 eyes and laser-assisted in situ keratomileusis (LASIK) in 106 eyes, for correction of simple, myopic, hyperopic or mixed astigmatism. Cylinder axis was determined under manifest and cycloplegic refractions and using Allegro Occulyzer II and Allegro TopolyzerVario platforms. Cylinder axis agreement was assessed by intraclass correlation coefficient, Pearson correlation coefficient and by the method described by Bland and Altman.

Results: Intraclass correlation coefficient and Pearson correlation coefficient showed statistically significant cylinder axis agreement between manifest refraction, cycloplegic refraction, Allegro Oculyzer II and Allegro Topolyzer-Vario $(\mathrm{p}<0.001)$. Despite statistically significant cylinder axis agreement between the four measuring tools, 4 of 156 eyes (2.5\%) showed unexpected discrepancy between Allegro Oculyzer II and Allegro TopolyzerVario cylinder axis.

Conclusion: Although cylinder axis shows statistically significant agreement between manifest refraction, cycloplegic refraction, Allegro Oculyzer II and Allegro TopolyzerVario, unexpected discrepancies occur.

Keywords: manifest refraction, cycloplegic refraction, Allegro Oculyzer II, Allegro Topolyzer-Vario, PRK, LASIK

\section{Introduction}

Laser refractive surgery, including photorefractive keratectomy (PRK) and laserassisted in situ keratomileusis (LASIK), gained global establishment as a reliable and safe procedure for correction of refractive errors. ${ }^{1,2}$

Laser refractive surgery is undergoing great evolutions, including excimer laser current flying spot technology, enhanced intraoperative pupillary tracking mechanism and cyclorotation adjustment. ${ }^{3-5}$ The WaveLight EX500 (Alcon Laboratories; Ft Worth, TX, USA), the recent excimer laser evolution, applies a $1050 \mathrm{Hertz}(\mathrm{Hz})$ multidimensional active tracking system with estimated 2 milliseconds (ms) latency and pupillary size tracking ability ranging from $1.5 \mathrm{~mm}$ to $8 \mathrm{~mm}{ }^{6}$

The term "wavefront optimized" was introduced to describe aspherical ablation profiles attempting to eliminate or reduce spherical aberration associated with myopic laser refractive correction. ${ }^{7}$

The majority of refractive surgeons rely on clinical refraction, manifest or cycloplegic; however, this refractive data occasionally shows difference from topography, regarding cylinder axis. Some surgeons advocated clinical refractive 
data adjustment with topography, introducing the new term "topography-modified refraction". 8

Cylinder axis significance is not solely related to laser refractive surgery; it represents a cornerstone in lenticular refractive surgery, phakic intraocular lens (IOL) implantation or refractive lens exchange, particularly toric IOL. Similarly, cylinder axis determination is a crucial step in contact lens fitting.

Multiple factors might influence the accurate measurements of corneal astigmatism such as tear film stability, xerophthalmia, ocular surface status and corneal epitheliopathy. In addition, soft or hard contact lens wear may alter the accuracy of corneal astigmatism measurements.

Currently, it is not clearly documented which instrument measures corneal astigmatism with the greatest reproducibility and repeatability, and whether available measuring modalities could be applied interchangeably. Therefore, multiple

Comparison studies were undertaken to determine reproducible and accurate methods for corneal astigmatism measurement. ${ }^{9}$

The aim of this study was to evaluate cylinder axis agreement between manifest refraction (MR), cycloplegic refraction (CR), Allegro Oculyzer II and Allegro TopolyzerVario.

\section{Methods}

All patients were recruited from the Department of Ophthalmology, Faculty of Medicine, Alexandria University (Alexandria, Egypt). Informed consent was obtained from all patients. This study was approved by the Ethics of Research Committee, Faculty of Medicine, University of Alexandria, Egypt.

Recruited patients were scheduled for wavefront optimized laser refractive surgery, PRK or LASIK, for correction of simple, myopic, hyperopic or mixed astigmatism. Exclusion criteria were coexisting ocular pathologies, uncontrolled diabetes mellitus, collagen vascular diseases, pregnancy or breastfeeding, severe xerophthalmia, corneal dystrophies, forme fruste keratoconus, and keratoconus.

\section{Preoperative Examination}

All patients underwent manifest and cycloplegic refractions by a TOPCON RM-8900 Auto Refractometer (Topcon Medical Systems, Tokyo, Japan), measurements of the uncorrected visual acuity (UCVA) and best spectacle-corrected visual acuity (BSCVA).
All eyes were subjected to corneal topography assessment by Allegro Topolyzer-Vario (WaveLight, Erlangen, Germany) and Scheimpflug tomography examination by Allegro Oculyzer II (WaveLight, Erlangen, Germany). The Oculyzer presents a Scheimpflug rotating camera, with a 360 degrees rotating light beam, scanning the cornea with a high density of points from the corneal centre. In contrast, the Topolyzer is a placido-disk-based system with a camera imaging reflections from the surface of the cornea. Since the Topolyzer camera is located at the centre of the topographer, a central scotoma is produced corresponding to the camera location, and hence a small area of central corneal data are extrapolated. ${ }^{10}$

Patients enrolled in the study had pre-operative pachymetry $\geq 460$ microns $(\mu \mathrm{m})$ for PRK and $\geq 500 \mu \mathrm{m}$ for LASIK. PRK subjects were required to retain an average post-operative residual corneal bed $\geq 380 \mu \mathrm{m}$. LASIK subjects were required to retain an average post-operative residual corneal bed $\geq 300 \mu \mathrm{m}$.

\section{Operative and Postoperative Data}

All patients underwent wavefront optimized laser refractive surgery, PRK in 50 eyes and LASIK in 106 eyes, for correction of simple, myopic, hyperopic or mixed astigmatism, applying WaveLight EX500 (Alcon Laboratories; Ft Worth, TX, USA). All surgeries were performed by a single surgeon, the author. A superior hinge was applied in LASIK cases using Moria Evolution 3 Microkeratome (Moria, Antony, France) with a programmed planned flap thickness of 110 $\mu \mathrm{m}$ and a diameter of $8 \mathrm{~mm}$. In PRK, the corneal epithelium was removed in a diameter of $8 \mathrm{~mm}$ in a centripetal fashion using a blunt hockey blade. UCVA and manifest refraction were evaluated at 1 month post-operatively. Postoperative refraction was assessed by a TOPCON RM-8900 Auto Refractometer (Topcon Medical Systems, Tokyo, Japan).

\section{Statistical Analysis of the Data}

Data were fed to the computer and analyzed using IBM SPSS software package version 20.0. (Armonk, NY: IBM Corp). Intraclass correlation coefficient (ICC) and Pearson correlation coefficient were used to assess agreement. A p value less than 0.05 was considered statistically significant. Cylinder axis agreement was also studied using the method described by Bland and Altman. This method also computed $95 \%$ limits of agreement (LoA=mean difference $\pm 1.96 \mathrm{SD}$ ).

\section{Results}

The present study was conducted on 82 patients 32 (39\%) males and 50 (61\%) females and involved 156 eyes scheduled 
for wavefront optimized laser refractive surgery, PRK in 50 eyes and LASIK in 106 eyes, for correction of simple, myopic, hyperopic or mixed astigmatism. The age of the studied patients ranged from 18 to 49 years $(28.1 \pm 8.7$ years $)$. (Table 1)

Intraclass correlation coefficient and Pearson correlation coefficient showed statistically significant cylinder axis agreement between manifest refraction (MR), cycloplegic refraction (CR), Allegro Oculyzer II and Allegro Topolyzer-Vario $(\mathrm{p}<0.001 *)$. (Tables 2 and 3) (Figure 1).

Despite statistically significant cylinder axis agreement between the four measuring tools, 4 of 156 eyes (2.5\%) (3 patients) showed unexpected discrepancy between Allegro Oculyzer II and Allegro Topolyzer-Vario cylinder axis (Figure 2). In these cases, the cylinder axis applied for laser treatment was the mean of the four measurements. One month postoperatively, these cases showed 0 cylinder with UCVA 1 . In the first case, MR cylinder axis was 104, CR cylinder axis was 94, Allegro Oculyzer II cylinder axis was 136 and Allegro Topolyzer-Vario cylinder axis was 88. The cylinder axis applied for laser treatment was the mean of the four values 105. In the second case, MR cylinder axis was 52, CR cylinder axis was 15, Allegro Oculyzer II cylinder axis was 38 and Allegro Topolyzer-Vario cylinder axis was 5 . The cylinder axis applied for laser treatment was the mean of the four values 28 . In the third case, MR cylinder axis was 100, CR cylinder axis was 100, Allegro Oculyzer II cylinder axis was 49 and Allegro Topolyzer-Vario cylinder axis was 152 . The cylinder axis applied for laser treatment was the mean of the four values 100. In the last case, MR cylinder axis was $97, \mathrm{CR}$ cylinder axis was 95, Allegro Oculyzer II cylinder axis was 155 and Allegro Topolyzer-Vario cylinder axis was 134. The cylinder axis applied for laser treatment was the mean of the four values 120 .

\section{Discussion}

The Alcon/WaveLight refractive surgery laser platform comprises the EX500 excimer laser, and a series of diagnostic networked devices that constitute the Refractive Suite $^{\circledR}$ (including Allegro Placido Topolyzer-Vario and Allegro Scheimpflug Oculyzer II). ${ }^{11}$

This Refractive Suite applies ethernet networking, allowing diagnostic data import from networked screening devices into the laser planning software, including topography data from Allegro Placido Topolyzer-Vario and topometric data from Allegro Scheimpflug Oculyzer II. ${ }^{12}$ Multiple studies reported the application of
Table I Distribution of the Studied Cases According to Different Parameters $(n=156)$

\begin{tabular}{|c|c|}
\hline & No. (\%) \\
\hline Age (Years) & \\
\hline Mean \pm SD & $27.4 \pm 7.7$ \\
\hline Median (Min. - Max.) & $26(18-49)$ \\
\hline Refractive Surgery & \\
\hline PRK & $50(32.1 \%)$ \\
\hline LASIK & $106(67.9 \%)$ \\
\hline Pachymetry $(\mu \mathrm{m})$ & \\
\hline Mean \pm SD & $537.7 \pm 34$ \\
\hline Median (Min. - Max.) & $533(487-639)$ \\
\hline Keratometric KI (D) & \\
\hline Mean \pm SD & $42.8 \pm 1.4$ \\
\hline Median (Min. - Max.) & $42.8(39.6-46.3)$ \\
\hline Keratometric K2 (D) & \\
\hline Mean \pm SD & $44.6 \pm 1.6$ \\
\hline Median (Min. - Max.) & $44.6(41.5-50.6)$ \\
\hline Sphere (D) & \\
\hline Mean \pm SD & $-2 \pm 3$ \\
\hline Median (Min. - Max.) & $-1.5(-8-5.5)$ \\
\hline Cylinder (D) & \\
\hline Mean \pm SD & $-1.9 \pm 1$ \\
\hline Median (Min. - Max.) & $-1.5(-4.5--0.5)$ \\
\hline Manifest Refraction Cylinder Axis & \\
\hline Mean \pm SD & $95 \pm 66.4$ \\
\hline Median (Min. - Max.) & $101.5(3-192)$ \\
\hline Cycloplegic Refraction Cylinder Axis & \\
\hline Mean \pm SD & $92.7 \pm 66.1$ \\
\hline Median (Min. - Max.) & $98.5(1-194)$ \\
\hline Allegro Oculyzer II Cylinder Axis & \\
\hline Mean $\pm S D$ & $94.8 \pm 68.5$ \\
\hline Median (Min. - Max.) & $107.5(2-190)$ \\
\hline Allegro Topolyzer-Vario Cylinder Axis & \\
\hline Mean \pm SD & $94.5 \pm 69.3$ \\
\hline Median (Min. - Max.) & $106(0-185)$ \\
\hline I Month Sphere (D) & \\
\hline Mean \pm SD & $0 \pm 0.1$ \\
\hline Median (Min. - Max.) & $0(-0.3-0.5)$ \\
\hline I Month Cylinder (D) & \\
\hline Mean \pm SD & $0 \pm 0.1$ \\
\hline Median (Min. - Max.) & $0(-0.5-0)$ \\
\hline I Month UCVA & \\
\hline Mean \pm SD & $1 \pm 0.1$ \\
\hline Median (Min. - Max.) & I $(0.8-1)$ \\
\hline
\end{tabular}

Abbreviations: SD, standard deviation; PRK, photorefractive keratectomy; LASIK, laser-assisted in situ keratomileusis; UCVA, uncorrected visual acuity. 
Table 2 Intra Class Correlation Coefficient for Cylinder Axis Agreement

\begin{tabular}{|l|l|l|l|}
\hline & ICC Coefficient & $\mathbf{9 5 \%}$ C.I & $\mathbf{p}$ \\
\hline MR Axis vs. & & & \\
CR axis & 0.996 & $0.995-0.997$ & $<0.00 I^{*}$ \\
Oculyzer axis & 0.991 & $0.988-0.993$ & $<0.00 I^{*}$ \\
Topolyzer axis & 0.989 & $0.985-0.992$ & $<0.00 I^{*}$ \\
\hline CR Axis vs. & & & \\
Oculyzer axis & 0.990 & $0.986-0.993$ & $<0.00 I^{*}$ \\
Topolyzer axis & 0.991 & $0.987-0.993$ & $<0.00 I^{*}$ \\
\hline Oculyzer Axis vs. & & & \\
Topolyzer axis & 0.994 & $0.992-0.996$ & $<0.00 I^{*}$ \\
\hline
\end{tabular}

Note: *Statistically significant at $\mathrm{p} \leq 0.05$.

Abbreviations: ICC, intra class correlation coefficient; $\mathrm{Cl}$, confidence interval; $M R$, manifest refraction; $C R$, cycloplegic refraction.

Table 3 Pearson Correlation Coefficient for Cylinder Axis Agreement

\begin{tabular}{|l|l|l|l|l|}
\hline & $\begin{array}{l}\text { Mean } \\
\text { Difference } \\
\text { (SD) }\end{array}$ & $\begin{array}{l}\text { 95\% Limits } \\
\text { of } \\
\text { Agreement }\end{array}$ & $\begin{array}{l}\text { Pearson } \\
\text { Correlation } \\
\text { Coefficient } \\
(\mathbf{r})^{*}\end{array}$ & p-value \\
\hline MR axis - CR axis & $2.37(2.92)$ & 14.0 to -9.2 & 0.996 & $<0.00 I^{*}$ \\
\hline $\begin{array}{l}\text { MR axis - } \\
\text { Oculyzer axis }\end{array}$ & $0.25(9.02)$ & $\begin{array}{l}17.9 \text { to } \\
-17.4\end{array}$ & 0.992 & $<0.00 I^{*}$ \\
\hline $\begin{array}{l}\text { MR axis - } \\
\text { Topolyzer axis }\end{array}$ & $0.55(9.94)$ & $\begin{array}{l}20.0 \text { to } \\
-18.9\end{array}$ & 0.990 & $<0.00 I^{*}$ \\
\hline $\begin{array}{l}\text { CR axis - } \\
\text { Oculyzer axis }\end{array}$ & $-2.12(9.50)$ & $\begin{array}{l}16.5 \text { to } \\
-20.7\end{array}$ & 0.991 & $<0.00)^{*}$ \\
\hline $\begin{array}{l}\text { CR axis - } \\
\text { Topolyzer axis }\end{array}$ & $-1.81(9.33)$ & $\begin{array}{l}16.5 \text { to } \\
-20.1\end{array}$ & 0.992 & $<0.00 I^{*}$ \\
\hline $\begin{array}{l}\text { Oculyzer axis - } \\
\text { Topolyzer axis }\end{array}$ & $0.30(7.53)$ & $\begin{array}{l}15.1 \text { to } \\
-14.5\end{array}$ & 0.994 & $<0.00 I^{*}$ \\
\hline
\end{tabular}

Note: *Statistically significant at $\mathrm{p} \leq 0.05$.

Abbreviations: SD, standard deviation; $r$, Pearson coefficient; MR, manifest refraction; CR, cycloplegic refraction.

topography-guided treatment with such platforms, whether in normal or irregular corneas. ${ }^{13-20}$

The Oculyzer presents a Scheimpflug rotating camera, with a 360 degrees rotating light beam, scanning the cornea with a high density of points from the corneal centre. Therefore, it should be the first choice when planning laser treatment in corneas with central irregularities or aberrations. However, it can be affected by ocular movement or corneal haze or cloudiness. ${ }^{10}$

In contrast, the Topolyzer is a placido-disk-based system with a camera imaging reflections from the surface of the cornea. Since the Topolyzer camera is located at the centre of the topographer, a central scotoma is produced corresponding to the camera location, and hence a small area of central corneal data are extrapolated.

Therefore, it should be the first choice when planning laser treatment in corneas with more peripheral irregularities or aberrations. However, it lacks the provision of full surface information, with lower accuracy in cases of central corneal aberrations. ${ }^{10}$

A recent study by Cummings et al showed that both the Oculyzer and Topolyzer provide reliable and comparable results in pre-operative myopes and in subjects with mixed astigmatism. $^{10}$ This coincides with the present study, where statistically significant agreement between Allegro Oculyzer II and Allegro Topolyzer-Vario was detected.

In a recent study by Kanellopoulos, clinical refractive data were modified with topographic data, considering cylinder axis and amount, introducing the new term "topography-modified refraction". This provided superior visual function regarding UCVA, residual refractive error, total high-order aberrations, coma aberration, and contrast sensitivity. He hypothesized that "topography-modified refraction" allows to bypass the bias induced by lenticular astigmatism, particularly active in young myopic patients. Such hypothesized lenticular astigmatism seems to be responsible for the distortion of the objective cylinder axis and amount. ${ }^{8}$

Numerous comparative studies were undertaken to correlate between corneal measurements using variable techniques. Lee et $\mathrm{al}^{21}$ reported that corneal astigmatism measurements obtained via partial coherence interferometry, automated keratometry, Orb scan slit topography, iTrace ray tracing, and Pentacam Scheimpflug imaging were comparable to manual keratometric measurements, concluding possible interchangeable application of these instruments for assessment of corneal astigmatism. Another study addressed the accuracy of preoperative astigmatism measurements in cases of toric IOL and concluded non-significant difference between manual keratometry, automated keratometry, Pentacam Scheimpflug imaging or partial coherence interferometry. ${ }^{22}$ Similarly, Shirayama et $\mathrm{al}^{23}$ reported comparable corneal astigmatism measurements obtained using manual keratometry, partial coherence interferometry, Atlas placido-based topographer, and Galilei Dual Scheimpflug analyzer. On the other hand, Visser et $\mathrm{al}^{24}$ reported poor agreement considering the vector of corneal astigmatism between Pentacam Scheimpflug imaging, manual keratometer, partial coherence interferometer, placido-based corneal topographer, or 

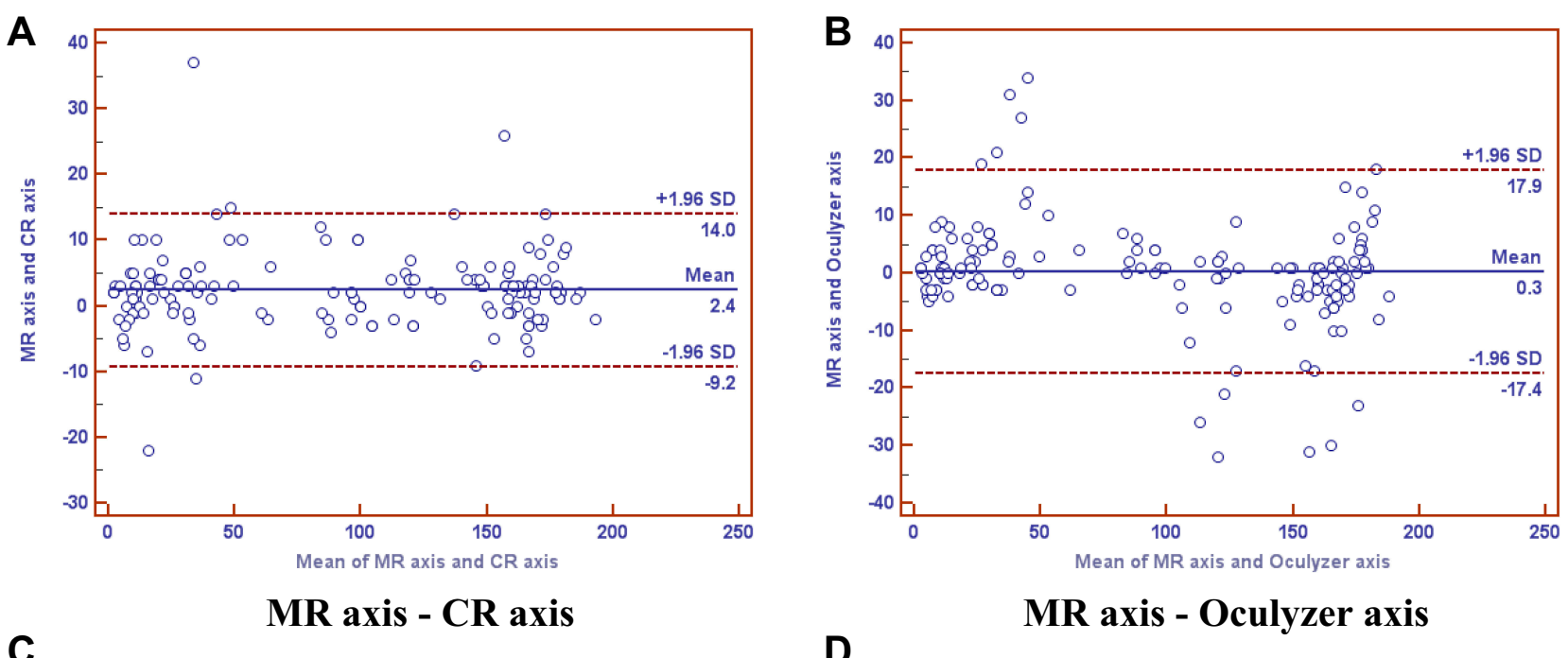

C
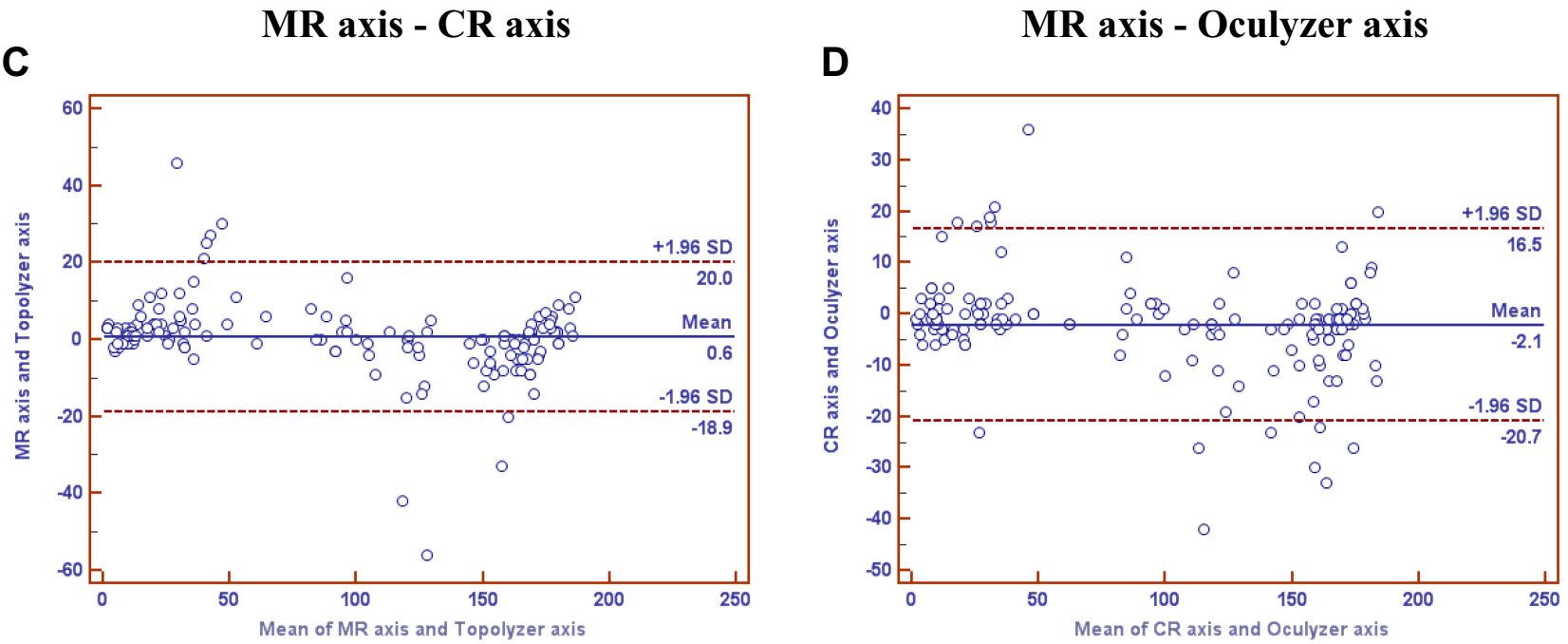

MR axis - Topolyzer axis

E
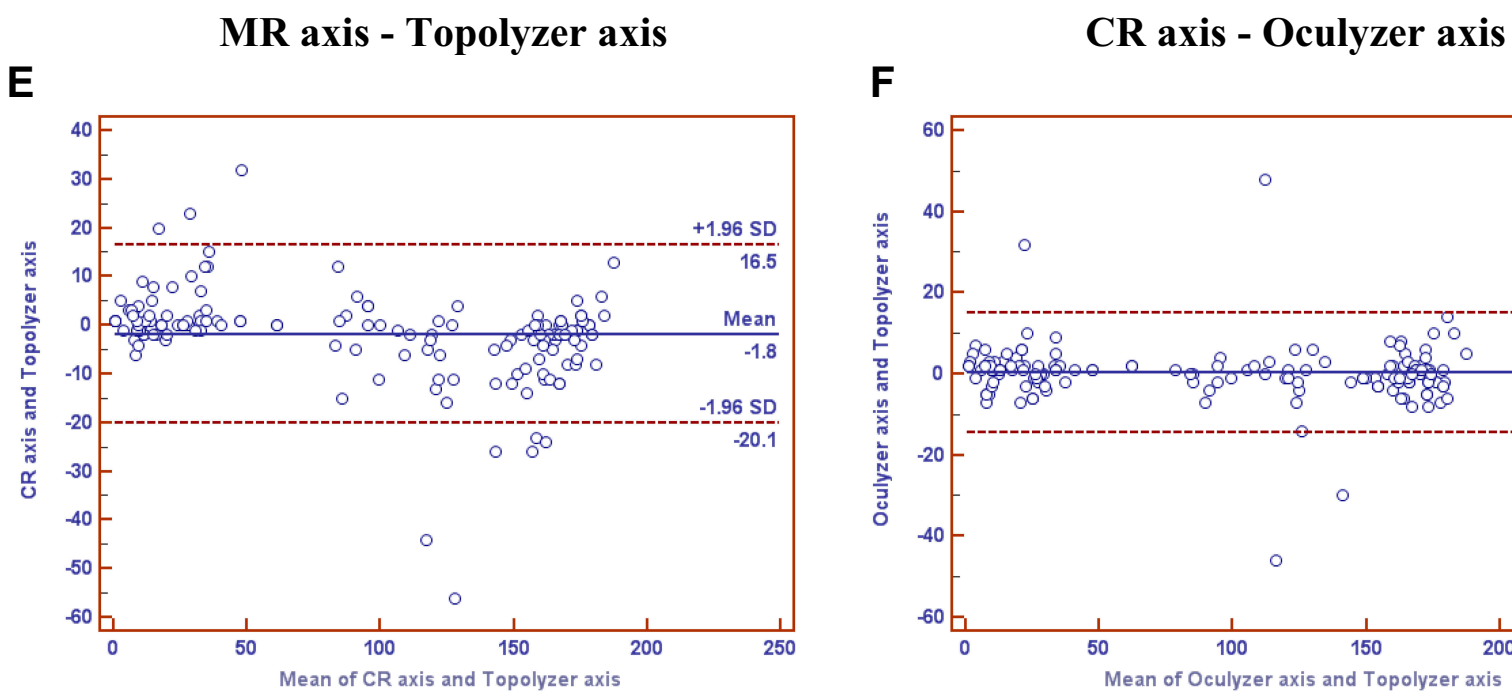

CR axis - Topolyzer axis

$\mathbf{F}$

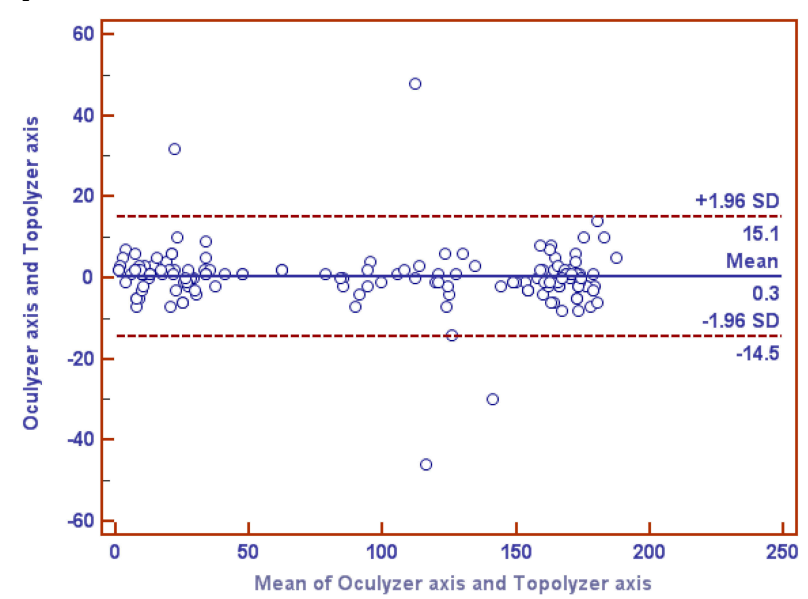

Oculyzer axis - Topolyzer axis

Figure I Bland-Altman plots of cylinder axis agreement between manifest refraction (MR), cycloplegic refraction (CR), Allegro Oculyzer II and Allegro Topolyzer-Vario. The bold horizontal line demonstrates the mean difference and the dotted lines above and below represent the $95 \%$ limits of agreement (LoA) interval. A: MR axis - CR axis. B: MR axis - Oculyzer axis. C: MR axis - Topolyzer axis. D: CR axis - Oculyzer axis. E: CR axis - Topolyzer axis. F: Oculyzer axis - Topolyzer axis. 


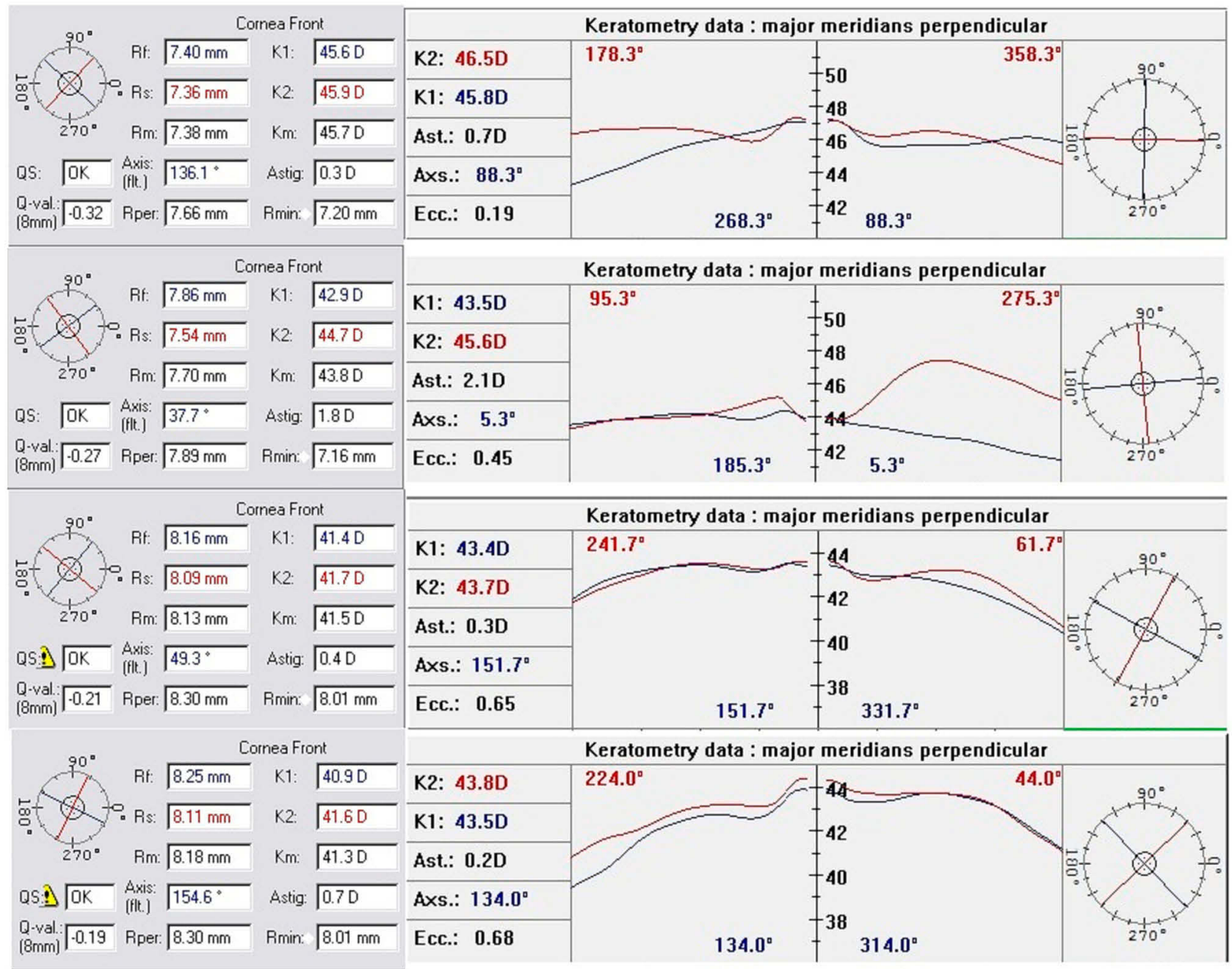

Figure 2 Allegro Oculyzer II and Allegro Topolyzer-Vario cylinder axis disagreement in four studied cases.

optical low coherence reflectometer. Similarly, Crawford et $\mathrm{al}^{25}$ reported limited agreement between Orb scan slit topographer and Pentacam Scheimpflug imaging or Galilei Dual Scheimpflug analyzer in both steep and flat keratometric measurements.

Taking these comparative studies into consideration demonstrates considerable variability in corneal measurements obtained using various instruments. Behshad et al recommended the comparison of data from more than one measuring modality, looking for agreement, in order to confirm the magnitude and axis of corneal astigmatism in order to minimize errors, in cases of toric IOL implantation. ${ }^{26}$

Similarly, Browne et $\mathrm{al}^{27}$ assessed absolute sphere, astigmatism amount, and steepest cylindrical axis in 87 eyes (54 patients) undergoing toric IOL implantation, using manual keratometry and four automated keratometers. The mean of the five measurements for sphere, astigmatism amount, and steepest cylindrical axis were labeled meld sphere, meld astigmatism, and meld axis, respectively. Although Bland-Altman plots for statistical analysis yielded an insignificant difference from meld measurement for each parameter, the authors documented a disturbing number of outliers that might be overlooked if a single measurement modality was applied. Authors concluded that measurement errors can be dramatically reduced by averaging measurements from manual keratometry with any automated technology to make toric IOL selection more accurate.

This goes in agreement with the present study, where 4 of 156 eyes $(2.5 \%)$ ( 3 patients) showed unexpected discrepancy between Allegro Oculyzer II and Allegro Topolyzer-Vario cylinder axis. In these cases, the cylinder axis applied for laser treatment was the mean of the four measurements. 1 month postoperatively, these cases 
showed 0 cylinder with UCVA 1 . In the first case, MR cylinder axis was 104, CR cylinder axis was 94, Allegro Oculyzer II cylinder axis was 136 and Allegro TopolyzerVario cylinder axis was 88. The cylinder axis applied for laser treatment was the mean of the four values 105 . In the second case, MR cylinder axis was 52, CR cylinder axis was 15, Allegro Oculyzer II cylinder axis was 38 and Allegro Topolyzer-Vario cylinder axis was 5 . The cylinder axis applied for laser treatment was the mean of the four values 28 . In the third case, MR cylinder axis was $100, \mathrm{CR}$ cylinder axis was 100, Allegro Oculyzer II cylinder axis was 49 and Allegro Topolyzer-Vario cylinder axis was 152. The cylinder axis applied for laser treatment was the mean of the four values 100. In the last case, MR cylinder axis was 97, CR cylinder axis was 95, Allegro Oculyzer II cylinder axis was 155 and Allegro TopolyzerVario cylinder axis was 134 . The cylinder axis applied for laser treatment was the mean of the four values 120 .

"These findings may change the current clinical paradigm of the optimal subjective refraction utilized in laser vision correction." 8

\section{Conclusions}

Although cylinder axis shows statistically significant agreement between manifest refraction, cycloplegic refraction, Allegro Oculyzer II and Allegro Topolyzer-Vario, unexpected discrepancies occur.

\section{Abbreviations}

$\mathrm{MR}$, manifest refraction; $\mathrm{CR}$, cycloplegic refraction; $\mathrm{PRK}$, photorefractive keratectomy; LASIK, laser-assisted in situ keratomileusis; Hz, Hertz; Ms, milliseconds; UCVA, uncorrected visual acuity; BSCVA, best spectacle-corrected visual acuity; $\mu \mathrm{m}$, microns; ICC, intra class correlation coefficient; LoA, limits of agreement.

\section{Data Sharing Statement}

Datasets are available in additional supporting files by reasonable request to the author.

\section{Ethics and Consent Statement}

This study was approved by the Ethics of Research Committee (IRB 00007555, FWA 00015712), Faculty of Medicine, University of Alexandria, Egypt. All procedures performed in studies involving human participants were in accordance with the ethical standards of the institutional and/or national research committee and with the 1964 Declaration of Helsinki and its later amendments or comparable ethical standards. Written informed consent to participate in the study was obtained from all individual participants included in the study.

\section{Consent}

Written informed consent to publish the results of the study and identifying images or other personal or clinical details of participants that compromise anonymity was obtained from all individual participants included in the study.

\section{Funding}

No funding was obtained for this study and there were no sources of public or private financial support.

\section{Disclosure}

The author reports no financial or proprietary interest in a product, method, or material and declares no conflicts of interest in this work.

\section{References}

1. Kugler LJ, Wang MX. Lasers in refractive surgery: history, present, and future. Appl Opt. 2010;49(25):F1-F9. doi:10.1364/AO.49. $0000 \mathrm{~F} 1$

2. Lukenda A, Martinović ZK, Kalauz M. Excimer laser correction of hyperopia, hyperopic and mixed astigmatism: past, present, and future. Acta Clin Croat. 2012;51(2):299-304.

3. Vega-Estrada A, Alió JL, Arba Mosquera S, Moreno LJ. Corneal higher order aberrations after LASIK for high myopia with a fast repetition rate excimer laser, optimized ablation profile, and femtosecond laser-assisted flap. J Refract Surg. 2012;28(10):689-696. doi:10.3928/1081597X-20120921-03

4. Winkler von Mohrenfels C, Khoramnia R, Lohmann CP. Comparison of different excimer laser ablation frequencies $(50,200$, and $500 \mathrm{~Hz})$. Graefes Arch Clin Exp Ophthalmol. 2009;247(11):1539-1545. doi:10.1007/s00417-009-1102-x

5. Iseli HP, Mrochen M, Hafezi F, Seller T. Clinical photoablation with a $500-\mathrm{Hz}$ scanning spot excimer laser. $J$ Refract Surg. 2004;20 (6):831-834. doi:10.3928/1081-597X-20041101-12

6. Matsuura T, Ikeda H, Idota N, Motokawa R, Hara Y, Annaka M. Anisotropic swelling behavior of the cornea. $J$ Phys Chem B 2009;113(51):16314-16322. doi:10.1021/jp907232h

7. de Ortueta D, Magnago T, Triefenbach N, Arba Mosquera S, Sauer U, Brunsmann U. In vivo measurements of thermal load during ablation in high-speed laser corneal refractive surgery. J Refract Surg. 2012;28(1):53-58. doi:10.3928/1081597X-20110906-01

8. Kanellopoulos AJ. Topography-modified refraction (TMR): adjustment of treated cylinder amount and axis to the topography versus standard clinical refraction in myopic topography-guided LASIK. Clin Ophthalmol. 2016;10:2213-2221. doi:10.2147/OPTH.S122345

9. Lee H, Kim T, Kim EK. Corneal astigmatism analysis for toric intraocular lens implantation: precise measurements for perfect correction. Curr Opin Ophthalmol. 2015;26:34-38. doi:10.1097/ ICU.0000000000000119

10. Cummings AB, Mascharka N. Clinical outcomes after topography-based corneal laser surgery with the wavelight oculyzer and topolyzer platforms. $J$ Refract Surg. 2010;26(7):478-485. doi:10.3928/1081597X-200908 14-05 
11. Kanellopoulos AJ, Asimellis G. Correlation between central corneal thickness, anterior chamber depth, and corneal keratometry as measured by oculyzer II and WaveLight OB820 in preoperative cataract surgery patients. J Refract Surg. 2012;22:1-6.

12. Kanellopoulos AJ. Topography-guided hyperopic and hyperopic astigmatism femtosecond laser-assisted LASIK: long-term experience with the $400 \mathrm{~Hz}$ eye-Q excimer platform. Clin Ophthalmol. 2012;6:895-901. doi:10.2147/OPTH.S23573

13. Han DC, Chen J, Htoon HM, Tan DT, Mehta JS. Comparison of outcomes of conventional WaveLight $\left({ }^{\circledR}\right)$ Allegretto Wave $\left({ }^{\circledR}\right)$ and Technolas $\left({ }^{\circledR}\right)$ excimer lasers in myopic laser in situ keratomileusis. Clin Ophthalmol. 2012;6:1159-1168. doi:10.2147/OPTH.S29660

14. Celik HU, Alagöz N, Yildirim Y, et al. Accelerated corneal crosslinking concurrent with laser in situ keratomileusis. J Cataract Refract Surg. 2012;38(8):1424-1431. doi:10.1016/j.jcrs.2012.03.034

15. Kanellopoulos AJ. Long-term safety and efficacy follow-up of prophylactic higher fluence collagen cross-linking in high myopic laser-assisted in situ keratomileusis. Clin Ophthalmol. 2012;6:1125-1130. doi:10. 2147/OPTH

16. Kanellopoulos AJ, Asimellis G. Refractive and keratometric stability in high myopia LASIK with high-frequency femtosecond and excimer lasers. J Refract Surg. 2013;29(12):832-837. doi:10.3928/ 1081597X-20130924-02

17. Kanellopoulos AJ, Asimellis G. Keratoconus management: long-term stability of topography-guided normalization combined with high-fluence CXL stabilization (the Athens Protocol). J Refract Surg. 2014;30(2):88-92. doi:10.3928/1081597X-20140120-03

18. Kanellopoulos AJ, Asimellis G. Corneal refractive power and symmetry changes following normalization of ectasias treated with partial topography-guided PTK combined with higher-fluence CXL (the Athens Protocol). J Refract Surg. 2014;30(5):342-346. doi:10.3928/ 1081597X-20140416-03
19. Kanellopoulos AJ, Asimellis G. LASIK ablation centration: an objective digitized assessment and comparison between two generations of an excimer laser. J Refract Surg. 2015;31(3):164-169. doi:10.3928/ 1081597X-20150225-01

20. Kanellopoulos AJ, Asimellis G. Novel placido-derived topography-guided excimer corneal normalization with cyclorotation adjustment: enhanced athens protocol for keratoconus. J Refract Surg. 2015;31(11):768-773. doi:10.3928/1081597X-20151021-06

21. Lee H, Chung JL, Kim EK, et al. Univariate and bivariate polar value analysis of corneal astigmatism measurements obtained with 6 instruments. J Cataract Refract Surg. 2012;38(9):1608-1615. doi:10. 1016/j.jcrs.2012.04.035

22. Chang M, Kang SY, Kim HM. Which keratometer is most reliable for correcting astigmatism with toric intraocular lenses. Korean J Ophthalmol. 2012;26:10-14. doi:10.3341/kjo.2012.26.1.10

23. Shirayama M, Wang L, Weikert MP, Koch DD. Comparison of corneal powers obtained from 4 different devices. Am J Ophthalmol. 2009;148:528-535;e521. doi:10.1016/j.ajo.2009.04.028

24. Visser N, Berendschot TT, Verbakel F, et al. Comparability and repeatability of corneal astigmatism measurements using different measurement technologies. J Cataract Refract Surg. 2012;38:1764-1770. doi:10.1016/j.jcrs.2012.05.036

25. Crawford AZ, Patel DV, McGhee CN. Comparison and repeatability of keratometric and corneal power measurements obtained by Orbscan II, Pentacam, and Galilei corneal tomography systems. Am J Ophthalmol. 2013;156:53-60. doi:10.1016/j.ajo.2013.01.029

26. Behshad S, Tucker J, Garg S. Toric intraocular lens alignment: manual versus automated alignment techniques for toric IOLs. Int Ophthalmol Clin. 2016;56:71-84. doi:10.1097/IIO.0000000000000115

27. Browne AW, Osher RH. Optimizing precision in toric lens selection by combining keratometry techniques. J Refract Surg. 2014;30 (1):67-72. doi:10.3928/1081597X-20131217-07
Clinical Ophthalmology

\section{Publish your work in this journal}

Clinical Ophthalmology is an international, peer-reviewed journal covering all subspecialties within ophthalmology. Key topics include: Optometry; Visual science; Pharmacology and drug therapy in eye diseases; Basic Sciences; Primary and Secondary eye care; Patient Safety and Quality of Care Improvements. This journal is indexed on PubMed
Central and CAS, and is the official journal of The Society of Clinical Ophthalmology (SCO). The manuscript management system is completely online and includes a very quick and fair peer-review system, which is all easy to use. Visit http://www.dovepress.com/ testimonials.php to read real quotes from published authors. 